\title{
Junção e tradição discursiva na escrita infantil
}

\section{Junction and discursive tradition in children's writing}

\section{Lúcia Regiane Lopes-Damasio ${ }^{1}$}

\begin{abstract}
Resumo: Neste artigo, propõe-se uma abordagem descritivo-comparativa do funcionamento dos mecanismos de junção nas tradições discursivas (TDs) relato de experiência e carta de opinião, no modo escrito de enunciação. Com o objetivo de alcançar indícios que apontem a relação sintomática entre mecanismos de junção e TDs, o estudo fundamenta-se no modelo funcionalista de junção (RAIBLE, 2001), conjugado a uma base teórica que entende a escrita como constitutivamente heterogênea (CORRÊA, 2004) e a uma concepção de texto que considera as TDs que o constituem (KABATEK, 2006). Nesse quadro teórico-metodológico, a descrição da escrita infantil é pautada na consideração de aspectos linguísticos e discursivos, que permitem o reconhecimento, por meio do funcionamento dos MJs, de rastros do movimento do sujeito pelo que (re)conhece como fixo e lacunar do texto. Os resultados mostram que a textualização ocorre por meio dessa circulação do sujeito, em intrínseca associação àquilo que imagina ser a (sua) escrita, no processo de atualização da tradição. As especificidades da movimentação indiciada por esses rastros apontam, ao mesmo tempo, para o geral e o particular, a partir do que é fixo e lacunar nas tradições em que se inserem e lançam luz sobre a relação sintaxe-texto-discurso.
\end{abstract}

Palavras-chave: Escrita. Tradição discursiva. Mecanismos de junção.

\begin{abstract}
In this paper, we suggest a descriptive-comparative approach to the functioning of junction mechanisms (MJs) in discursive traditions (TDs), experience reports, and opinion letters, on the written form of enunciation. With the goal of finding evidence that lead to a symptomatic relationship between junction mechanisms and TDs, this study is based on the functional-based junction model (RAIBLE, 2001), combined with a theoretical base that understands writing as constitutionally heterogeneous (CORREA $\hat{E}, 2004)$ and with a conception of text that considers the TDs which form the text (KABATEK, 2006). Within this theoretical and methodological frame, the description of children's writing is guided by the consideration of linguistic and discursive aspects which allow for the recognition, through the functioning of MJs, of traces of subject movement, considering what is acknowledged as fixed and lacunar in a text. The results show that the textualization occurs through this circulation of the subject, on an intrinsic association with what is imagined to be its writing, on the process of actualization of the tradition. The specificities of the movement highlighted by these traces indicate, from what is fixed and lacunar in the traditions in which they are inserted, at the same time, what is general and specific, and shed light on the relations among syntax-text-speech.
\end{abstract}

Keyword: Writing. Discursive tradition. Junction mechanisms.

\footnotetext{
${ }^{1}$ Universidade Estadual Paulista Júlio de Mesquita Filho, Faculdade de Ciências e Letras, Departamento de Estudos Linguísticos, Literários e da Educação, Assis, SP, Brasil. Endereço eletrônico: 1.damasio@unesp.br.
} 


\section{Introdução}

Este artigo propõe uma abordagem descritivo-comparativa da escrita infantil a partir do funcionamento dos mecanismos de junção $(\mathrm{MJs})^{2}$ em duas tradições discursivas (TDs) ${ }^{3}$ : relato de experiência e carta de opinião. Com essa abordagem, objetiva-se alcançar indícios da relação sintomática passível de ser estabelecida, conforme Kabatek (2005), entre MJs e TD. Trata-se de, seguindo uma linha de estudos anteriores (LOPES-DAMASIO, 2019; TAURA, 2019; LOPES-DAMASIO; SILVA, 2018; LONGHIN-THOMAZI, 2011), apontar relações linguístico-discursivas entre MJs e TDs, no âmbito da constituição de TDs na/da escrita.

Assim, o estudo concentra-se em dois questionamentos: (i) como os MJs funcionam e constituem as TDs relato de experiência (RE) e carta de opinião (CO)? (ii) com base na comparação do funcionamento desses mecanismos nessas TDs, de que modo podem ser tomados como indícios de TDs? A hipótese é que, a partir da circulação do sujeito pelo que imagina ser a (sua) escrita, a realização das TDs ocorre em virtude do que esse sujeito (re)conhece como fixo e lacunar nessas tradições, deixando rastros que indiciam seu processo de atualização.

Partindo da descrição do funcionamento dos MJs nas TDs investigadas, o objetivo central deste trabalho é identificar indícios da relação sintomática entre MJs e essas TDs. O alcance desse objetivo, à luz da hipótese apresentada, justifica a adoção de um lugar teóricometodológico para a abordagem investigativa, que conjuga aspectos linguísticos a discursivos, de modo a permitir o reconhecimento, na escrita, de rastros que mostram o movimento do sujeito para a construção dos sentidos no processo de textualização, fundamentado na correlação entre atualização e experiência que está na base do conceito de TD, conforme Kabatek (2005, 2006, 2008), no âmbito dos estudos diacrônicos, mas também conforme é adotado e refinado em trabalhos que se voltam para a escrita numa perspectiva sincrônica (LOPES-DAMASIO, 2019; LOPES-DAMASIO; SILVA, 2018, entre outros).

Para o material de análise deste artigo, foram selecionados, do Banco de Dados de Produções Escritas do Ensino Fundamental II (EFII) ${ }^{4}, 20$ textos escritos por alunos do $9^{\circ}$ ano, caracterizados a partir de duas TDs: 10 de RE e 10 de CO. Para a produção dos textos de RE, os alunos foram estimulados a relatar uma história pessoal sobre o tema "Amizade e internet".

\footnotetext{
${ }^{2}$ Quaisquer técnicas usadas para juntar porções textuais (cf. RAIBLE, 2001).

${ }^{3}$ Modelos textuais que integram a memória de sujeitos, podendo corresponder a gêneros discursivos, tipos textuais e construções linguísticas, como Era uma vez (cf. KABATEK, 2005, 2006, 2008).

${ }^{4}$ Desenvolvido a partir de projeto de extensão da UNESP (TENANI, LONGHIN-THOMAZI, 2008-2011).
} 
Para a produção dos de CO, o tema proposto foi "Massacre de Realengo" e foi solicitado aos alunos que escrevessem uma carta em que exporiam sua opinião sobre a tragédia de Realengo.

De modo geral, é uma característica fixa de RE a presença da relação temporal, devido à sua finalidade comunicativa. No entanto, o modo de marcação dessa relação, na materialidade linguística do texto, é lacunar, ou seja, variável; se por meio dos MJs, pode apresentar as arquiteturas paratática ou hipotática, correlacionadas com especificidades semânticas, identificáveis nas diferentes formas de experimentação da relação temporal (simultaneidade, anterioridade, posterioridade, habitualidade), em usos de diferentes MJs, como aponta Longhin (2014), em relação à TD narração, que guarda semelhanças com RE.

Nessa mesma linha, é uma característica fixa de CO a assunção de posicionamentos, acerca do tema proposto, avaliados como críticos pelo sujeito, de modo a levar o outro/leitor, ali representado, a aderir a seu posicionamento a partir dos argumentos expostos. A forma de marcação dessa opinião é também lacunar, podendo atrelar-se ou não à atuação de técnicas juntivas, e está diretamente ligada à circulação do sujeito pela sua imagem dessa TD.

Essas duas TDs são construídas à luz dos princípios de composicionalidade e repetibilidade $^{5}$, que sinalizam o já falado/ouvido e escrito/lido. A constatação de quais TDs atuam como matéria para a composição das tradições RE e CO depende da observação de indícios da circulação dos sujeitos pelo que imaginam ser o fixo e o lacunar dessas tradições, a partir de suas práticas orais e letradas. Como já apontado, os rastros que serão perseguidos para essa constatação serão, neste trabalho, aqueles deixados pelo funcionamento dos MJs.

Quanto ao método de análise, conjugam-se as abordagens quantitativa e qualitativa, em duas etapas: (i) descrição comparativa do funcionamento dos MJs em RE e CO; e (ii) a partir dos resultados de (i), análise que aponte indícios linguístico-discursivos da relação entre MJs e TDs. Por meio desse percurso descritivo-analítico, a discussão dos resultados, em (ii), poderá lançar luz sobre a natureza dessa relação sintomática em dados de escrita infantil.

\section{A escrita como modo de enunciar uma TD}

Este trabalho segue a proposta de Corrêa (1997), na linha de Street (1984), Abaurre (1990), Chacon (1996), entre outros, e assume um entendimento da escrita como

\footnotetext{
5 Uma combinação de elementos, evocada numa situação concreta, produz repetição e sua concretização, significado. Essa combinação aponta a composicionalidade das TDs, que pode ser: paradigmática, referente à possibilidade de o texto agregar um conjunto de tradições, não necessariamente de um mesmo domínio discursivo; e sintagmática, referente, num âmbito local, aos arranjos linguísticos na linearidade do texto.
} 
constitutivamente heterogênea ${ }^{6}$. Segundo Corrêa (1997, p. 68-69), aponta-se também aqui a base semiótica, na atividade da escrita, como um argumento para a recusa da dicotomia entre o falado/oral e o escrito/letrado, tomando como pressuposta a operação das atividades comunicativas sempre a partir de um feixe de materiais significantes, conforme se comprova, por exemplo, com a ideia de ritmo da escrita (CHACON, 1996). Corrêa (1997) mostra que a complexidade dessa recusa se evidencia pela participação de signos não-verbais e suas bases semióticas na matéria escrita. $\mathrm{Na}$ falta de tal pureza de materiais significantes, na escrita, não se pode admitir, portanto, uma simples oposição entre dois materiais significantes independentes, nem a dicotomia, ainda que metodológica, entre essas formas de enunciação.

Parte-se, assim, do pressuposto de que o escrevente, em seu processo de escrita, circula por um imaginário que se particulariza para situações específicas e concretas de uso da escrita no âmbito de suas condições de produção (CORRÊAA, 1997), e propõe-se uma vinculação entre essas condições de produção e as TDs. Interessa destacar, ainda segundo Corrêa, que há, no falado e no escrito, uma realização menos evidente da linguagem, que se estabelece em sua relação com o sujeito e é marcada por rastros linguísticos específicos e orientadores do grau de convivência entre o oral/falado e o letrado/escrito.

Conforme Corrêa (2008, p. 77-78), descartam-se: (i) a noção de escrita como modo de representação da língua, por meio do qual se opõem, imprecisamente, língua falada e língua escrita; e (ii) a noção de fala e escrita como modalidades, já que se definem a partir de referências às suas bases semióticas: o som (fala) e o traço gráfico (escrita), sendo que essa diferença tem servido como base inapropriada para a validação da oposição radical entre práticas faladas e escritas, como se, nelas, o aspecto semiótico fosse o único relevante. No lugar dessas noções, assume-se, com Corrêa (1997), a proposta de fala e escrita como modos de enunciação, em que a escrita, apesar de se mostrar como enunciação solitária, nunca se realiza sem a presunção de um leitor, o que a aproxima do modo de enunciação da fala, em que, mais do que a presença física dos interlocutores, conta sua representação.

A partir desses pressupostos, Corrêa (2004) propõe um espaço metodológico para a observação do encontro entre as práticas orais/faladas e letradas/escritas, construído por meio de três eixos de representação da escrita. O primeiro deles, o modo de constituição da escrita em sua gênese, refere-se aos momentos em que o escrevente, ao apropriar-se da escrita, tende

\footnotetext{
${ }^{6}$ Diz-se escrita, porque o objeto deste trabalho centra-se na escrita, como no caso do de Corrêa, mas entenda-se aqui modo heterogêneo de constituição da língua, já que essas considerações também servem para a fala se se considera, por exemplo, a postulação de um grafismo no fluxo temporal da fala como percepção de que, a exemplo das práticas letradas, as orais apresentam também um modo heterogêneo de constituição.
} 
a tomá-la como representação integral da oralidade/fala, plasmando esses dois modos de realização da linguagem verbal. O segundo eixo caracteriza-se pela apropriação da escrita como código institucionalizado e refere-se aos momentos em que o escrevente tende a tomá-la a partir do que imagina ser o modo já autônomo de representar a oralidade. O terceiro caracteriza-se pela relação que o texto do escrevente mantém com o já faladolescrito e já ouvido/lido, ou seja, com o que imagina ser a relação apropriada com a exterioridade que constitui o seu texto - outros textos, a própria língua, outros registros, outros enunciadores.

A circulação do escrevente pelos dois primeiros eixos deixa-se ver por meio de marcas linguísticas - prosódicas, sintáticas e lexicais - e é dirigida pelo terceiro eixo, o da dialogia com o já falado/escrito, que se refere, de modo geral, à presença do dialogismo em toda a linguagem. É a esse caráter de réplica da linguagem que se propõe associar, neste trabalho, o conceito de TD, a partir de um refinamento da proposta de Kabatek $(2005,2006,2008)$.

A noção de TD nasce e é difundida numa perspectiva histórica dos gêneros textuais (ASCHENBERG, 2002). Conforme Lopes-Damasio; Silva (2018), o conceito apoia-se no entendimento da linguagem como atividade, via recuperação de um diálogo com o pensamento aristotélico de Humboldt, de acordo com o qual a linguagem não possui caráter acabado, mas de um conjunto de modos de fazer (COSERIU, 1982). A escrita é reconhecida como processo e não como produto, e a noção de texto segue a consideração da linguagem como atividade, reconhecida como acontecimento e não adequação (cf. CORRÊA, 2007) ${ }^{7}$.

Para a construção do conceito de TD, a concepção coseriana de língua, concreta e histórica, estende-se também ao recorte sincrônico ${ }^{8}$. Nela, preveem-se três níveis linguísticos: (i) universal, em que a linguagem é considerada como atividade do falar, enquanto fato antropológico, genericamente humano; (ii) histórico, em que é considerada como língua particular, incluindo suas variedades; e (iii) atual ou individual, como ato linguístico de um indivíduo numa situação determinada (COSERIU, 1981). Algumas ressalvas quanto a esses níveis tornam-se necessárias, a fim de viabilizar as relações teóricas com o entendimento conferido à escrita, tomada como constitutivamente heterogênea. A primeira diz respeito ao nível histórico e depende do reconhecimento de que só existe história no nível atual, assim como do de que ela só existe porque o ato linguístico nunca é individual. A segunda diz respeito

\footnotetext{
7 O processo de textualização caracteriza-se como acontecimento, não acabado senão na relação entre falante/ouvinte, autor/leitor.

${ }^{8} \mathrm{O}$ que permite a adoção desse paradigma em pesquisas sobre fenômenos da escrita infantil (LOPES-DAMASIO, 2019; LOPES-DAMASIO; SILVA, 2018; LONGHIN-THOMAZI, 2011, entre outros).
} 
ao nível atual e chama a atenção para o reconhecimento de que esse nível deve estar subjacente à ideia de sujeito da linguagem não como indivíduo, mas como individuação.

O sujeito, considerado como individuação dialógica, constitui-se em sua relação com a linguagem, concebida como lugar de interação, interlocução e tomada como atividade. Essa concepção de sujeito, correspondente à proposta por Corrêa (2004, p. 15-16), rejeita o entendimento de sujeito da linguagem como indivíduo, dado que não é a singularidade factual que enuncia, mas não rejeita integralmente o assujeitamento, dado que adota o entendimento de que o sujeito é constituído pelo outro, cuja presença é marcada pela heterogeneidade e pela representação (CORRÊA, 2004, p. 15-16). Segundo Lopes-Damasio; Silva (2018), a ideia de individuação deve ser tomada no/para o tratamento do sujeito (individuação do sujeito) e dos rastros linguísticos deixados por esse sujeito na escrita (individuação dos rastros). Trata-se, pois, de enxergar um modo de constituição desse sujeito em rastros linguísticos locais.

Segundo Peter Koch (2008), a configuração assumida num texto não depende exclusivamente da tradição linguística e fixa-se em tradições do discurso. Dessa forma, o autor propõe a bipartição do nível histórico, acrescentando à história da língua, a história das TDs, e considerando que a segunda perpassa a primeira, no sentido de que o ato comunicativo é filtrado pela organização linguística, de acordo com o sistema linguístico e a norma que se coloca entre ele e o seu uso concreto, e, concomitantemente, pela ordem textual, responsável pela atualização de determinada TD.

Segundo Kabatek (2005), uma TD pode se formar a partir de qualquer elemento significável, formal ou de conteúdo, cuja re-evocação estabelece um laço entre atualização e tradição. $\mathrm{O}$ autor propõe, então, duas fases: a TD propriamente dita e a constelação discursiva evocada por ela e a TD adquire valor de signo, reconhecido por meio de outros signos que extrapolam os limites textuais. Destaca-se, assim, o diálogo entre TD, o já-dito, o que se diz e o(s) projeto(s) de dizer, sem reduzir a novidade de cada acontecimento discursivo. Num refinamento teórico, conforme Lopes-Damasio; Silva (2018), a expressão tradição estará relacionada à historicidade, abarcando textos e fórmulas/expressões que caracterizam gêneros institucionalizados e atos de fala fundamentais; e estará relacionada à experiência, no sentido do já sabido dessas relações. A expressão discursiva estará relacionada não só à qualificação das tradições como linguísticas, a fim de abarcar todo tipo de tradição do falar/escrever, conforme Kabatek (2005), mas também à qualificação das tradições como acontecimento, que guarda, a cada realização, uma novidade dada no modo como se realiza aquela prática. 


\section{A individuação dos rastros: uma abordagem dos MJs}

Assumir a hipótese de que a utilização de uma ou outra forma de junção pode ser determinante das características textuais de TDs, significa partir do pressuposto da necessidade de se delinear uma base teórica para a especificação dos MJs, aqui tomados fora do espectro de generalizações que, frequentemente, acompanha o tratamento analítico dessa categoria linguística, bem como de tantas outras. Os MJs serão, pois, reconhecidos como rastros da individuação dos sujeitos, na tradição de dizer/escrever por que circulam.

Para o seu tratamento descritivo, esses rastros coincidem, na materialidade linguística dos textos, com marcas caracterizáveis como quaisquer técnicas usadas para juntar porções textuais, abrangendo desde conjunções e advérbios, até locuções preposicionais, marcadores ou operadores discursivos e zero. Em sua dimensão linguística, funcionam no cruzamento de dois eixos: (1) o vertical (tático), que se desdobra em parataxe e hipotaxe, distinguíveis com base nos seguintes aspectos gramaticais: (i) se ambas as orações são livres e constituem, assim, cada uma, um todo funcional, a construção é paratática (ordem fixa); (ii) se, por outro lado, uma oração domina/modifica a outra, é dominante e, portanto, nuclear, enquanto a outra é dependente e, portanto, modificadora, a construção é hipotática (há dependência); e (2) o horizontal (semântico), de acordo com um crescente de complexidade semântica.

Em relação a (2), destaca-se seu caráter unidirecional, comprovado, na perspectiva filogenética, por meio da mudança semântica, constatada em diversos trabalhos (cf. KORTMANN, 1997), que apontam para uma relação de derivação entre as categorias espaciais e modais em direção a tempo e causa, condição, contraste e concessão (CCCC); e de derivação entre tempo e CCCC. Nessa unidirecionalidade, a acepção aditiva configura-se como aquela mais concreta, localizada na ponta esquerda do continuum, em oposição àquela, concessiva, mais abstrata, localizada em sua ponta direita (LOPES-DAMASIO, 2014).

No âmbito da realização da linguagem como acontecimento, os MJs são tomados como o rastro 'específico' que aponta a relação do sujeito com a linguagem/escrita, de modo geral, por meio, particularmente, de sua circulação pelo já-falado/escrito, via TD. Assim, 'específico' quer dizer, ao mesmo tempo, geral e particular, ou seja, inscrito na história (VEYNE, 1971, p. 48 apud CORRÊA, 2007, p. 206).

Subjacente a essa primeira relação - entre os MJs e o específico de Veyne - situa-se uma segunda, entre $M J S$ e espaço de junção, que permite observar as técnicas de junção sem perder de vista o ponto em que ocorrem. Trata-se de uma observação do contexto linguístico, em que se vincula a ocorrência de uma TD à dimensão sintática da língua, sem, com isso, deixar de se tratar, ainda, de uma observação do contexto enunciativo, no qual a sintaxe assume feições 
de dimensão de contato entre a virtualidade do sistema e a sua realização, permitindo, dessa forma, a observação das junções como memória de realizações já feitas e não apenas como recursos formais da língua. Assim, o espaço de junção delineia-se a partir de um tratamento analítico de natureza linguístico-discursiva.

\section{Comparação do funcionamento dos MJs em RE e CO}

No que tange à descrição do funcionamento dos MJs nos textos analisados de RE e CO, aponta-se, de início, o seu perfil paratático, como mostra o Gráfico 1:

Gráfico 1 - Eixo vertical - a arquitetura tática em RE e CO

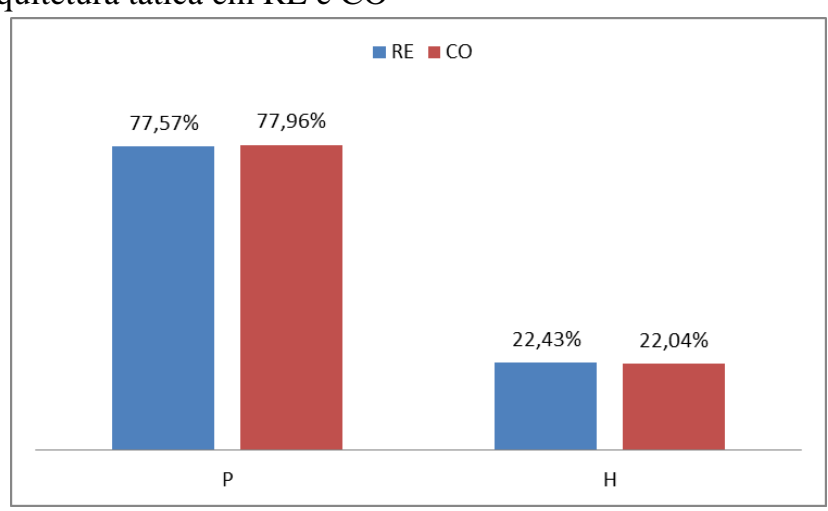

Fonte: elaborado pela autora.

Os resultados da análise do eixo vertical aproximam as duas tradições investigadas (RE e CO), produzidas por sujeitos do $9^{\circ}$ ano do $\mathrm{EF}$, assim como as aproxima de resultados de estudos voltados a textos produzidos por sujeitos nos primeiros anos de escolarização (cf. LOPES-DAMASIO; SILVA, 2018, LONGHIN-THOMAZI, 2011). Não há, como se podia esperar a partir de uma abordagem ontogenética idealista, aumento da frequência de construções hipotáticas, nem em função do processo de escolarização (com a passagem do sujeito para o segundo ciclo do EF), nem em função da natureza do texto produzido (se mais narrativo ou mais argumentativo). Os resultados da descrição desse eixo mostram rastros que caracterizam o que é fixo nessas tradições e indiciam um aspecto da circulação do sujeito pela escrita no que tange às formas de junção e à constituição sintática da textualização.

Os MJs mais frequentes foram a justaposição $(\varnothing)$ e $e$, representando mais da metade (55,76\%-RE e 52,15\%-CO) das estratégias observadas em RE e CO: 
Gráfico 2 - Frequência geral dos MJs em RE e CO

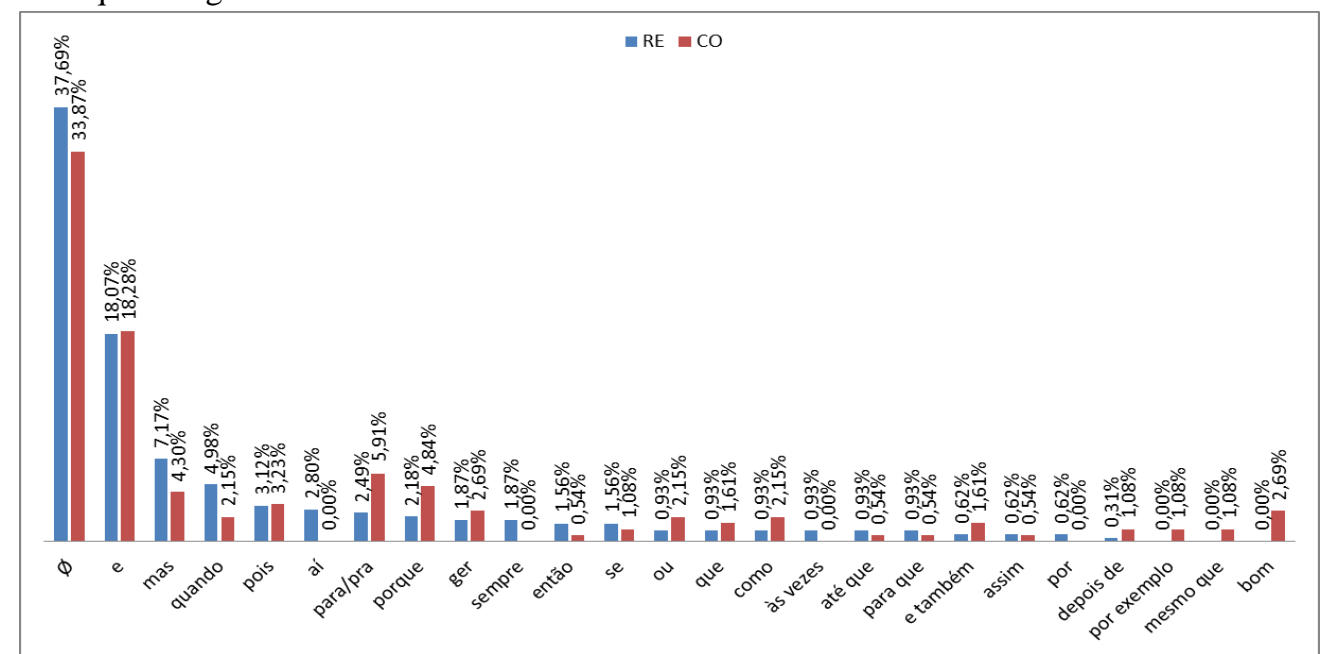

Fonte: elaborado pela autora.

Esse resultado também aproxima RE e CO, e a tipologia de MJs mais recorrentes nos textos dos escreventes em anos iniciais e finais do EF: tanto os sujeitos que estão sendo alfabetizados, quanto os que estão concluindo o EFII lançam mão da justaposição e de $e$, com maior recorrência, para juntar porções textuais de natureza formal diversa (em termos de (in)dependência tática) e de natureza textual-discursiva também diversa (quer para relatar uma história, quer para opinar diante de um fato). Assim, também essas escolhas, que caracterizam traço de repetibilidade da sintaxe juntiva dessas TDs, indiciam rastros do que é fixo, nessas tradições, se tomados como característicos da circulação do sujeito pela escrita.

Outros MJs revelaram frequências muito próximas em RE e CO: pois (3,12\%-RE; 3,23\%-CO); se (1,56\%-RE; 1,08\%-CO); assim (0,62\%-RE; 0,54\%-CO); e até que. Embora não apresentem frequências significativas em comparação com a da justaposição e $e$, caracterizam, ainda assim, rastros de escolhas que, por serem pouco diferenciadas em uma e outra tradição, não indiciam qualquer relação sintomática entre MJs e TDs.

Essas aproximações não obscurecem, no entanto, as escolhas que delineiam o funcionamento dos MJs em RE e CO e que, assim, podem ser sintomáticas dessas tradições. A partir do Gráfico 2, destacam-se os MJs mais recorrentes em RE, em comparação à CO: mas (7,17\%-RE; 4,3\%-CO); quando (4,98\%-RE; $2,15 \%$-CO); e então (1,56\%-RE; 0,54\%-CO). Da mesma forma, destacam-se os MJs mais recorrentes em CO, em comparação à RE: para/pra (5,91\%-CO; 2,49\%-RE); porque (4,84\%-CO; 2,18\%-RE); gerúndio (2,69\%-CO; 1,87\%-RE); ou (2,15\%-CO; 0,93\%-RE); que (1,61\%-CO; 0,93\%-RE); como (2,15\%-CO; 0,93\%-RE); e também (1,61\%-CO; 0,62\%-RE); e depois de (1,08\%-CO; 0,31\%-RE). Esse resultado permite constatar uma gama maior de MJs mais recorrentes em $\mathrm{CO}$ (oito), se comparada àqueles mais 
recorrentes em RE (três), e sinalizar um rol de escolhas maior, em $\mathrm{CO}$, face às verificadas em $\mathrm{RE}$, a partir do critério da repetibilidade dessas escolhas ${ }^{9}$.

A diferença na frequência desses MJs - tanto dos mais recorrentes em RE, quanto dos mais recorrentes em $\mathrm{CO}$ - é mais significativa do que a constatada em relação à justaposição e ao $e$. Destarte, mais uma vez, a repetibilidade dessas escolhas indicia sua correlação a papeis discursivo-pragmáticos atrelados às especificidades de cada uma dessas TDs ${ }^{10}$.

Os MJs cujas ocorrências foram exclusivas de uma ou outra TD investigada representam escolhas linguísticas que, se observadas em correlação com a repetibilidade em que preenchem os espaços de junção, nos textos, também podem contribuir para o delineamento das funções linguístico-discursivas dessa categoria, nessas tradições, e, consequentemente, abrir espaço para a identificação de indícios da relação sintomática entre MJs e as TDs investigadas. Nessa direção, destacam-se os usos de aí $(2,8 \%)$, sempre $(1,87 \%)$, às vezes $(0,93 \%)$ e por $(0,62 \%)$, constatados exclusivamente nos textos de RE; e de por exemplo $(1,08 \%)$, mesmo que $(1,08 \%)$ e bom (2,69\%), constatados exclusivamente em CO.

A esses resultados, acrescentam-se, com o Gráfico 3, aqueles referentes aos aspectos semânticos dos MJs, cf. critério bidimensional de análise:

Gráfico 3 - Eixo horizontal - as relações de sentido em RE e CO

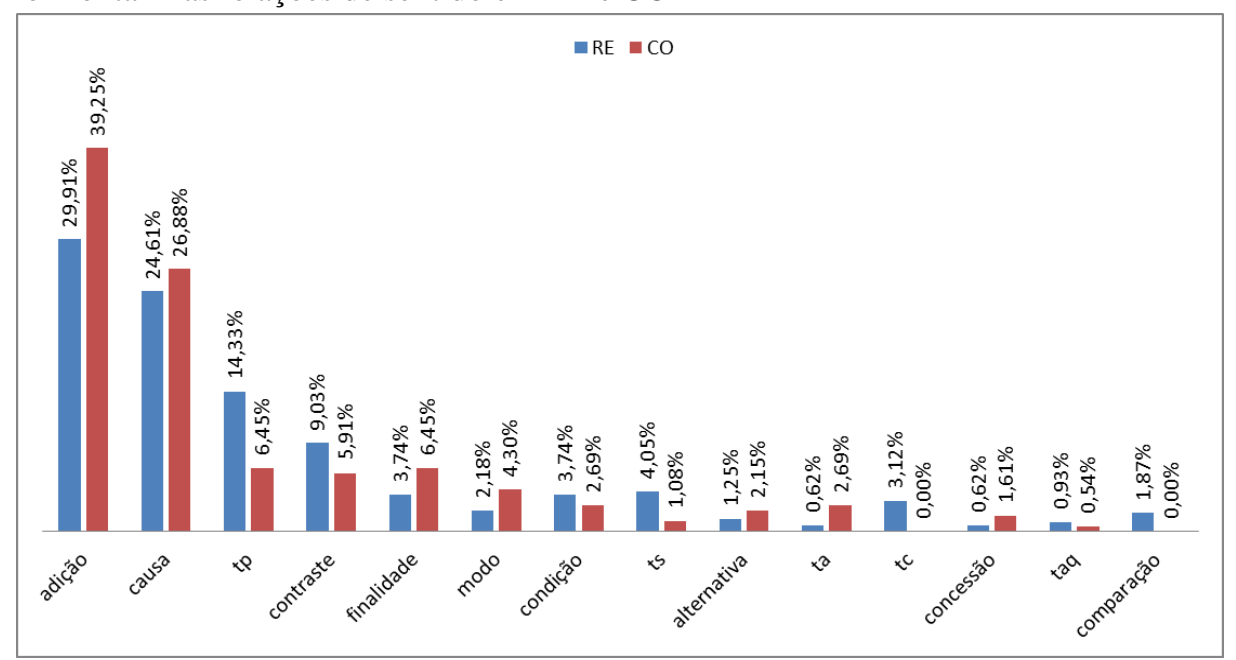

Fonte: elaborado pela autora.

Somadas, as relações de adição (29,91\%-RE; 39,25\%-CO), causa (24,61\%-RE; 26,88\%-CO), tempo posterior (14,33\%-RE; 6,45\%-CO), contraste (9,03\%-RE; 5,91\%-CO) e

\footnotetext{
${ }^{9}$ A inversão do critério da repetibilidade (relativa à observação de MJs com ocorrência única) aponta, igualmente, a inversão desses resultados: em RE e CO, verifica-se uma distribuição oposta de MJs com ocorrência única, mais expressiva em RE, em que representam 50\% das ocorrências, contra 41,66\%, em CO.

10 Para sustentar essas afirmações, é fundamental que se analise a relação entre os eixos vertical e horizontal, explorando aspectos semântico-discursivos desses MJs, conforme se propõe na continuidade deste artigo.
} 
finalidade (3,74\%-RE; 6,45\%-CO) são as mais frequentes em RE e CO. Assim, sem ocultar as variações de frequência, apontam o leque de expressões semânticas que caracterizam o que é fixo nessas tradições.

De modo específico, as relações mais frequentes em RE (em comparação com CO) são: tempo posterior $(14,33 \%-\mathrm{RE} ; 6,45 \%-\mathrm{CO})$; contraste $(9,03 \%-\mathrm{RE} ; 5,91 \%-\mathrm{CO})$; condição (3,74\%-RE; 2,69\%-CO); tempo simultâneo (4,05\%-RE; 1,08\%-CO) e tempo terminus ad quem (taq)/tempo limite (0,93\%-RE; 0,54\%-CO). Considerando-se que as relações de tempo contingente e de comparação ocorreram exclusivamente nos dados dessa TD $(3,12 \%$ e 1,87\%, respectivamente), são sete as relações semânticas mais recorrentes em RE em comparação com CO. Por sua vez, as relações mais frequentes em CO (em comparação com RE) também são sete: adição (39,25\%-CO; 29,91\%-RE); causa (26,88\%-CO; 24,61\%-RE); finalidade (6,45\%$\mathrm{CO} ; 3,74 \%$-RE); modo (4,30\%-CO; 2,18\%-RE); alternativa (2,15\%-CO; 1,25\%-RE); tempo anterior (2,69\%-CO; 0,62\%-RE) e concessão (1,61\%-CO; 0,62\%-RE).

De modo geral, esses resultados indiciam funcionamentos semânticos que aproximam as duas TDs: (1) a diferença pequena na frequência das relações de condição, tempo limite e causa; e (2) a frequência total do macrossistema CCCC muito próxima em cada TD (38\%-RE; 37,09\%-CO). Essas aproximações sinalizam traços do funcionamento dos MJs que invalidam expectativas fundamentadas no funcionamento dos MJs entorno de acepções mais abstratas em textos considerados mais complexos, do ponto de vista de suas relações pragmático-discursivas, como $\mathrm{CO}$, que tem viés argumentativo, em comparação com RE, que se abriria como espaço para o funcionamento de MJs com acepções mais concretas, em coerência com seu viés narrativo e sua proximidade icônica com o mundo real.

Por outro lado, ainda numa abordagem geral, dois aspectos sinalizam distinções no funcionamento dos MJs, no que tange às relações semânticas que explicitam: (1) a recorrência mais expressiva de aditivas em textos de $\mathrm{CO}$ (com diferença de quase $10 \%$ em relação a RE); e (2) a recorrência mais expressiva das relações temporais, em RE, que somam, nos textos dessa tradição, 23,02\% de todas as relações semânticas constatadas nesse universo, enquanto, em CO, são equivalentes a apenas $10,72 \%$ (com diferença superior a $10 \%$ em relação a $\mathrm{RE}$ ). A partir desses aspectos, dar-se-á início à discussão dos resultados na subseção seguinte.

\section{Indícios da relação sintomática entre MJs e as tradições RE e CO}

Para vislumbrar o modo como os MJs indiciam as tradições RE e CO, buscam-se, a partir da descrição do funcionamento linguístico dos MJs, nos textos investigados, rastros que indiciem a associação entre esse funcionamento e essas tradições, no espaço da escrita 
constitutivamente heterogênea. Nessa direção, nos Gráficos 4 e 5, destacam-se as relações mais recorrentes nas TDs investigadas: adição, causa, tempo posterior, contraste e finalidade:

Gráfico 4 - MJs em RE - relações de sentido e tipologia juntiva

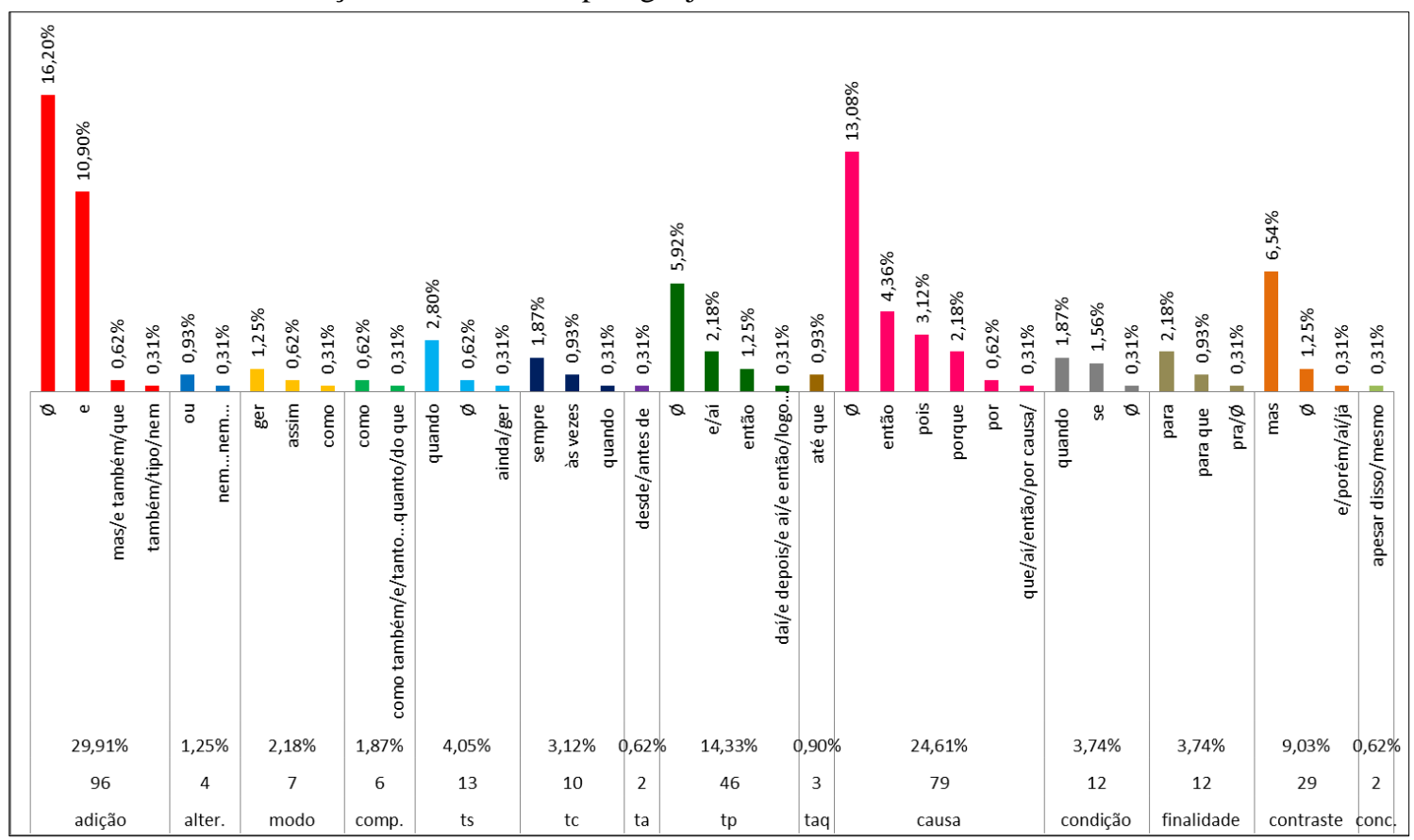

Fonte: elaborado pela autora.

Gráfico 5 - MJs em CO - relações de sentido e tipologia juntiva

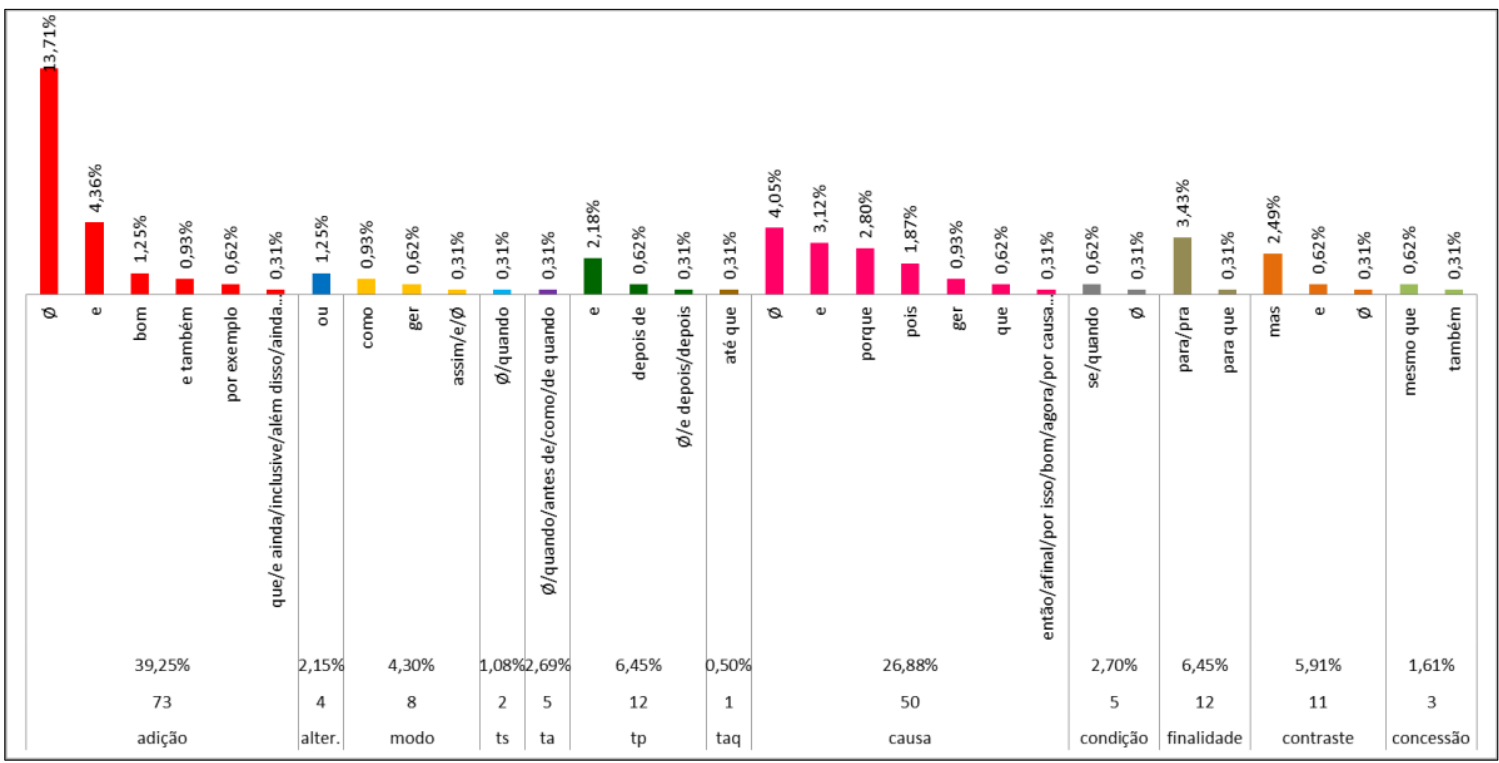

Fonte: elaborado pela autora.

Em relação à adição, cuja recorrência foi mais expressiva em $\mathrm{CO}$, a comparação dos resultados trazidos nesses Gráficos ressalta uma redução dos usos de justaposição e $e$, em CO, acompanhada por um aumento na frequência e diversidade de MJs usados com essa acepção em contextos discursivamente afinados com o que o sujeito imagina ser o objetivo de 
convencimento da tradição, ou seja, alinhados com o seu perfil argumentativo. Não se trata, nesses casos, apenas de inserir informação nova no texto e, com isso, fazê-lo progredir, mas de inserir um novo argumento, a partir do qual o sujeito imagina-se capaz de convencer o outro/leitor aí representado de que aquela opinião é relevante, consistente e, portanto, convincente, tal como pode ser exemplificado no trecho do texto (1) (T(1):

T(1) [CO/08] Caro Francisco, || Primeiramente agradeço a sua carta, e também estou | muito chocado com a tragédia em Realengo no RJ. || Para mim foi um horror um homem de 23 anos entrar | em uma escola e sair disparando nos alunos, além de | matar 12 deles depois ele se suicida. Com certeza Francisco | as crianças que não vivenciaram essa tragédia vão | ficar com trauma de ir à escola, ainda mais as | crianças de primeira a quarta série do enssino fundamental. [...]\| Atenciosamente,

Em T(1), característico de $\mathrm{CO}$, numa estrutura de carta, especificamente de cartaresposta - com vocativo "Caro Francisco", introdução "Primeiramente agradeço a sua carta" e encerramento "Atenciosamente" - o sujeito, de acordo com a sua imagem dessa TD, expressa sua opinião sobre o tema, por meio de argumentos e evidências, apresentados no miolo da carta, que convençam o leitor por ele representado de seu ponto de vista. Assim, no espaço menos fixo da carta, outra TD, argumentativa, a caracteriza como uma carta de opinião ${ }^{11}$.

Nesse espaço de mescla de TDs, são observados MJs aditivos, em dois funcionamentos: (i) voltado à introdução de informação nova no texto, como, por exemplo, o uso de e também, em trechos como "Primeiramente agradeço a sua carta, e também estou muito chocado com a tragédia em Realengo", na introdução da carta (em sua parte fixa), em que o tema do texto é inserido; e (ii) voltado à introdução de informação nova, tomada, discursivamente, como argumento forte para o convencimento acerca do ponto de vista do sujeito, na porção menos fixa de $\mathrm{CO}$, como, por exemplo, os usos de além de e ainda mais, em "além de matar 12 deles depois ele se suicida" e "as crianças que não vivenciaram essa tragédia vão ficar com trauma de ir à escola, ainda mais as crianças de primeira a quarta série". Destaca-se, pois, que os MJs aditivos, distribuídos, preferencialmente, na porção menos fixa de $\mathrm{CO}$, atuam, decisivamente, para a dinâmica argumentativa, caracterizando, de modo específico, um traço discursivo dessas técnicas juntivas e, ao mesmo tempo, da própria CO.

Em relação à causa, também se constata uma redução expressiva dos usos de justaposição em CO. O espaço juntivo mais próximo ao da justaposição, nesses textos, em termos do alto grau de inferência pragmático-discursiva de que carece para a depreensão de sua acepção, é aquele preenchido pelas ocorrências de $e$, mais frequentes em $\mathrm{CO}$. Ou seja, nos

\footnotetext{
${ }^{11}$ Se se considerarem textos em que as partes fixas da carta (vocativo, introdução e encerramento) não são produzidas e que são iniciados com a TD argumentativa, infere-se que essa TD preenche o espaço mais decisivo na textualização, uma vez que garante as condições de produção da TD, a partir do imaginário do sujeito.
} 
contextos causais de baixa marcação formal - sem técnicas juntivas que explicitem, na materialidade do texto, tal relação de sentido - o sujeito opta por zero, mas também por $e$, o que diferencia esses textos dos de RE. Soma-se a esse resultado que os textos de CO apresentam aumento na frequência e diversidade de MJs usados com acepção causal, se comparados àqueles de RE. Destacam-se, nessa direção, os usos de gerúndio, que, afinal, por isso e agora, encontrados apenas em $\mathrm{CO}$, além das variáveis por causa de e por causa que:

T(3) [CO/07] Os pais devem converçar com as crianças, porque a | melho meneira da crianças não ficarem com traumas é | os pais conversarem com elas, sobreo que ocorreu que | essa pessoa tinha problemas sofria bullyng, e, por causa | disso ele ficou com trauma da escola e que ele fez $\mid$ isso. E é por isso que nunca devemos fazer bullyng | com os outros.

$\mathrm{T}(4)[\mathbf{C O} / 02] \mathrm{Eu}$ Aline axo que esse crime aconteceu por causa que ele sofria Bullying na $\mid$ mesma escola em que ele (aconteceu) cometeu o crime, mais eu não entendo por | que ele saiu atirando nas crianças que não tem nada a ver, ele axo que isso | ia dar em alguma coisa; Resumindo ele queria se vingar do bullying que ele | sofria na mesma escola.

T(5) [CO/05] Eu acho que algumas crianças podem sim desen- | volver algum trauma da escola, afinal depois | de toda essa turbulência; um psicólogo ajuda- | ria muito, conversar com os filhos, etc...

T(6) [CO/09] Wellintong m. de oliveira de 23 anos | invadiu a escola com dois revólveres | matando 12 alunos deles. || Agora na (rasura)* minha opinião ele | devia ter algum problema psiquiátri | co para fazer essas coisas.

Em T(3), as estratégias juntivas ocorrem de forma paratática, na inserção de informações que explicam um conteúdo, inserido na oração anterior, como nos usos de porque e por isso, ou de forma hipotática, na inserção de orações causais no complexo causa-efeito, seja de forma convencional, conforme uso de por causa disso, ou não convencional, conforme uso de que. ${ }^{12}$ Em T(4), são observadas duas estratégias juntivas com acepção causal: por causa que, que insere a causa, numa estrutura hipotática, e o gerúndio Resumindo, que sinaliza a inserção de uma conclusão a partir do conteúdo exposto no texto, de forma aproximada à que se constata, em T(5), em que Afinal desempenha a mesma função, acrescida de um papel discursivo que marca sua força argumentativa nesse contexto. O uso de agora, em T(6), sugere a natureza causal entre as duas porções textuais, a apresentada no primeiro parágrafo, em que o sujeito descreve um fato, e a apresentada no segundo parágrafo, iniciado pelo MJ, em que o sujeito apresenta sua avaliação desse fato, com sinalização explícita dessa subjetividade em "na minha opinião". Nesse contexto, agora tem, acrescida à sua acepção de simultaneidade temporal, a acepção mais abstrata de causa, de acordo com a escala de complexidade semântica, que prevê o trânsito entre essas acepções a partir do parentesco semântico constatado entre elas, e de

\footnotetext{
${ }^{12}$ Uma proposta de leitura do MJ que, com acepção causal, pode ser explicitada pela paráfrase: “por causa disso [do motivo exposto anteriormente], ele fez isso [o que foi exposto anteriormente]".
} 
acordo com a natureza da tradição em que se insere, na qual o contexto discursivo ressalta a necessidade de justificar e explicar.

Toda essa diversidade de maneiras de rastros, no texto, da acepção causal alinha-se à natureza desses contextos, à imagem que o sujeito tem do que são os objetivos dessa TD e exemplifica o modo como as técnicas juntivas materializam a maior circulação do sujeito por formas lacunares ${ }^{13}$ de construção textual-discursiva da causalidade.

Os dados de tempo posterior sinalizam a sistematização realizada na subseção anterior que chamava a atenção para a recorrência mais expressiva das temporais em RE. A alta repetibilidade da posterioridade dos eventos, nessa TD, materializa-se no uso preponderante de justaposições, seguido de $e$, aí e então, além de uma ampla tipologia de juntores, como daí, $e$ depois, e aí, (e) então, logo depois, depois, depois de e depois que:

T(7) [RE/08] No ano de 2010, um menino de uma | cidade chamada de Ameriana, veio Para|São Jose, e ele não conhecia ninguem, $\emptyset \mid$ a tia dele é amiga da minha vó, e me apresento | ele, $\boldsymbol{\emptyset}$ eu fui logo perguntando o seu nome, e $\mid$ o menino dise, meu nome e fernando $\boldsymbol{\emptyset}$ Qual $\mid$ o seu $\boldsymbol{\emptyset}$ o meu é deivid, mais conhecido com | KaKa, hum eai vamos andar de baik $\boldsymbol{\emptyset}$ conhecer $\mid$ umpouco de São Jose, $\underline{\boldsymbol{\emptyset} \text { vamo. }}$.| Ei fernando voce é um menino muito legal, $\underline{\emptyset}$ você que ser meu amigo, $\boldsymbol{\emptyset} \operatorname{sim} \emptyset$ como quero $\emptyset \mid$ quibom, $\boldsymbol{\emptyset}$ a Taficano dinoite $\boldsymbol{\emptyset}$ amanha você vem aqui emcasa para nós conversa mais um pouco, $\emptyset$ belesa | então, ai nós conbino de ir para a escola junto, $\underline{\varnothing} \mid$ ta Bom então amanha eu venho. || Dimanha fui na padaria e emcontrei la, Ø $\mid$ Bondia KaKa Ø Bom dia, Ø vai encasa jájá ta Bom, -| depois de algumas Hora o fernando veio, e o dia-| se paso, e ele viro meu melhor amigo.[...]-|| Depois que o fernando mudo para São| Jose, a minha vida e mais felis.

Destacam-se, em T(7), dois usos distintos da temporalidade, também recorrentes em outros textos: (i) uso prioritário de justaposição para marcar a sequencialidade de trocas de falas na transposição que o sujeito faz, em seu texto, do discurso direto, conforme trechos sublinhados; e (ii) usos prioritários de outros MJs, como aí, então, e, depois de e depois que para marcar a sequencialidade dos fatos narrados, conforme trechos em itálico.

À baixa frequência dessa acepção, em $\mathrm{CO}$, acrescenta-se a preferência por $e$ e por usos pouco recorrentes de MJs prioritariamente compostos por depois (depois de, e depois). Fica claro, portanto, não só o alinhamento da acepção de tempo posterior com a natureza de RE, como a marcação dessa relação na materialidade linguística da tradição textual em questão. Ou seja, tal aspecto lacunar da tradição é preenchido de forma mais variável em RE do que em CO. Esse resultado torna-se ainda mais evidente se se considera a maior circulação do sujeito por outras formas de experimentação da relação temporal, em RE, em comparação com $\mathrm{CO}, \mathrm{o}$

\footnotetext{
${ }^{13}$ Denomina-se forma lacunar, pois, as possibilidades de realização, na textualização, da causalidade (no caso específico das análises realizadas neste ponto), em termos de suas características táticas - que podem envolver estruturas paratáticas e hipotáticas - e semânticas - que podem envolver trânsitos semânticos a partir de parentescos semânticos e inferências contextuais, mais ou menos convencionalizadas.
} 
que se confirma na exclusividade da constatação de tempo contingente, em RE, e na maior frequência e diversidade de seus usos na acepção de tempo simultâneo.

Entretanto, essa análise detalhada deixa ver, ainda em relação às formas de experimentação da relação temporal, uma especificidade relativa à anterioridade, que, de forma distinta das demais acepções desse macrossistema, apresenta não apenas uma frequência mais expressiva em $\mathrm{CO}(2,69 \%-\mathrm{CO} ; 0,62 \%-\mathrm{RE})$, como também uma maior diversidade tipológica (com usos de justaposição, quando, antes de, como e de quando).

$\mathrm{T}(8)[\mathbf{C O} / \mathbf{0 3}]$ Bom nesta ocorrencia, foi muito chocante, [...] pensou podia ser em qualquer cidade em qualquer escola, de $\mid$ homem desse ter aparecido assim do nada para $\mid$ matar crianças. Ele pode ter lá seus traumas $\mid$ de infância de quando era criança, mas também | não pecisava matar outras crianças que não | tem nada a ver com o caso ocorrido na vida $\mid$ dele, quando estudava lá na escola onde oco- | rreu o massacre!

$\mathrm{T}(9)$ [CO/05] Wellington assassinou doze crianças, com | idade entre 12 e 14 anos, antes da tragédia ele | era alguém calmo, na dele, mas pesquisava muito | sobre terrorismo, álem disso Wellington sofria | bullying na $\mid$ mesma escola onde matou as cri-|anças.

Os trechos em itálico ilustram como a acepção de tempo anterior integra o projeto de uma tradição delineada, no imaginário do sujeito, na finalidade discursiva de convencimento, por meio da exposição de argumentos. A marcação da anterioridade traz um fato, num papel discursivo de evidencialidade epistêmica, que atua na construção de uma imagem do sujeito como aquele que conhece a realidade/o caso em discussão. No entanto, esses fatos, ao cumprirem seu papel, ancoram um contra-argumento, por meio da construção de um espaço discursivo marcado pelo contraste, pela oposição e concessividade, a partir de conteúdos articulados via MJs que materializam essa estratégia argumentativa. Trata-se, assim, de um uso da temporalidade que caracteriza uma prática comum em $\mathrm{CO}$, porque integra o que o sujeito imagina ser o esquema de natureza fortemente argumentativa dessa tradição.

Em coerência com o nível de detalhamento da análise desta subseção, reconhece-se que, no macrossistema CCCC, as noções de contraste e concessão particularizam-se pelo grau de abstração das acepções envolvidas, sem que isso obscureça o compartilhamento do traço de oposição/contraste que está subjacente a ambas. Nesse sentido, a acepção de contraste fundamenta o cálculo semântico que caracteriza a acepção concessiva. Dessa forma, a diferença quantitativa entre RE e CO torna-se menos expressiva se se considera a soma das ocorrências dessas duas relações semânticas em cada uma das tradições (9,65\%-RE; 7,52\%-CO) e, consequentemente, enfraquece o indício que poderia torná-la sintomática de uma ou outra TD. Somam-se a esse argumento dois fatos: (i) os mesmos MJs são mais recorrentes nos contextos de RE e CO (mas, e e justaposição); e (ii) a forma mais abstrata de marcação do contraste (a concessão) é mais recorrente em CO do que em RE (1,61\%-CO; 0,62\%-RE). 
$\mathrm{T}(10)$ [CO/01] Bom, sobre o massacre de Realengo, eu penso que | foi uma terrível tragédia que não adiantou | em nada, pois aquele assassino matou as | crianças sem motivo algum, mesmo que ele | sofria bullying, ele não tinha de fazer isso $\mid$ com as crianças,

T(11) [RE/01] Se queremos marcar de sair para algum lugar temos | que se comunicar, na semana, durante o intervalo | da escola, ou nos sabados no computador, apesar | disso somos muito felizes como amigos[...].

T(12) [RE/06] Era um dia lindo era 13 de março de mar- | ço de 2011, sábado na Praia Grande em Santos (SP) [...] aí eu fui descer da | prancha para voltar para a praia (areia da praia) ai eu não | achei o fundo e eu fiquei sem saber o que que estava acon- | tecendo

Os trechos de T(10) e T(11) exemplificam contextos em que há indícios da acepção concessiva, na arquitetura hipotática, em $\mathrm{CO}$, e na paratática, em RE, respectivamente. Em ambos os casos, o caráter contrastivo é construído via inserção da negativa, em T(10), "mesmo que ele sofria bullyng, ele não tinha de fazer isso", e da condicional, em T(11), "Se queremos marcar de sair para algum lugar temos que se comunicar", retomada pelo MJ apesar disso. Dessa forma, embora as acepções contrastiva e concessiva não possam ser tomadas como sintomáticas de cada uma das tradições investigadas, essas tradições revelam contextos discursivos distintos, em que a forma de materialização dessas acepções se torna também distinta, seja devido: (i) a uma estrutura de maior dependência tática, verificável em CO; (ii) à habilitação da forma mais abstrata de marcação do contraste (a concessão), também constatada em CO; ou (iii) à implementação, em RE, de trânsitos semânticos entre acepções com grau de parentescos, como o que se observa em T(12), entre os macrossistemas de tempo e CCCC, por meio de aí. Nesse contexto, a partir da acepção mais concreta de tempo posterior, infere-se a acepção contrastiva de aí ("'eu fui descer da prancha [...], aí/mas eu não achei o fundo). Esses resultados sinalizam o potencial do funcionamento dos MJs, nessas acepções, alinhado às especificidades das tradições e, mais do que isso, o quanto esses aspectos lacunares estão atrelados ao modo como o sujeito circula por essas tradições.

Com relação à comparação dos resultados extraídos dos Gráficos 1 e 2 , no que tange à acepção de finalidade, constata-se, em CO, uma especialização dos MJs para/pra e para que, considerados convencionais para essa acepção, enquanto a justaposição foi observada exclusivamente nos dados de RE, que, ao mesmo tempo, revelou uma frequência expressivamente mais baixa dessa acepção. Reconhece-se, portanto, seu alinhamento com o imaginário do sujeito acerca dos propósitos discursivo-argumentativos da tradição CO.

$\mathrm{T}(13)$ [CO/01] então, pen | so que os pais dessas crianças deveriam conver- | sar com elas, para aliviar o sofrimento que | elas passaram, para acalmar o medo que | elas têem de voltar a escola em que es ${ }^{-}$| tudam, e também deveria ser feito algum | tipo de palestra na escola, para resolverem o | que deve ser feito, como por exemplo, ter se- | guranças, vígias na escola, para impedir que | entre qualquer estranho lá dentro, para que | assim, as crianças possam voltar à ir a escola | sem medo do que possa acontecer 
T(14) [RE/08] [...] o meu é deivid, mais conhecido com | KaKa, hum eai vamos andar de baik $\emptyset$ conhecer umpouco de São Jose, vamo. | Ei fernando voce é um menino muito | legal, você que ser meu amigo, sim como quero | quibom, a Taficano dinoite amanha você vem aqui | emcasa para nós conversa mais um pouco,

Nos textos, observam-se ocorrências de orações em que são explicitados os meios para atingir uma finalidade ou um propósito expressos na outra oração. Em todos os casos, trata-se de contextos circunstanciais, em que a noção de finalidade modifica um SN ou SV da outra oração, dentro do complexo hipotático, com exceção de uma única ocorrência paratática, apresentada em T(14): "vamos andar de baik Ø/para conhecer um pouco de São José”. O que diferencia a construção dessa acepção nas TDs investigadas é que, em todas as ocorrências encontradas em CO, conforme T(13), as finais são articuladas a orações nucleares em que o sujeito imagina explicitar uma propostalsugestão para a resolução do problema discutido. Por meio dessa articulação, o sujeito circula por um imaginário no qual busca o convencimento de seu leitor, aí representado, o que não é verificado nas ocorrências, em RE, nas quais não há a emergência desse caráter discursivo-pragmático de convencimento do outro.

\section{Considerações finais}

A abordagem dos MJs, em RE e CO, no modo escrito de enunciação, confirmou a hipótese da existência de relações sintomáticas entre MJs e TDs. A partir dos MJs, tomados como rastros que indiciam a atualização da tradição, observou-se como esse processo de textualização ocorre por meio da circulação do sujeito pelo que (re)conhece como fixo e lacunar nessas tradições, em intrínseca associação àquilo que imagina ser a (sua) escrita.

A partir do critério da repetibilidade, empregado na descrição dos usos de MJs, os resultados que se alinham em RE e CO são: (i) o funcionamento paratático dos MJs, no eixo vertical; (ii) as relações semânticas de adição, causa, tempo posterior, contraste e finalidade, no eixo horizontal; (iii) os usos de justaposição e $e$, no que diz respeito à tipologia de MJs; e (iv) a mesma frequência relativa do macrossistema $C C C C$. Esses aspectos, por se mostrarem igualmente recorrentes nas tradições investigadas, preenchem o espaço daquilo que o sujeito imagina ser fixo nessas tradições, independentemente de suas especificidades, e respondem ao primeiro questionamento do trabalho, de natureza descritivo-comparativa.

O mesmo critério levou a resultados que indiciam aspectos do que é lacunar em cada uma dessas TDs, respondendo, pois, ao segundo questionamento desta investigação: (i) o funcionamento das aditivas tem potencial sintomático de $\mathrm{CO}$ se se considera a sua frequência e diversidade de usos, articuladas à natureza discursivo-argumentativa desses usos, por meio dos quais o sujeito deixa rastros de sua imagem de uma tradição em que o convencimento do 
outro é o aspecto mais forte de textualização; (ii) o funcionamento das causais deixa ver seu potencial sintomático de $\mathrm{CO}$ se se considera sua diversidade de usos articulada à sua natureza discursivo-argumentativa, por meio da qual o sujeito deixa rastros de sua imagem de uma tradição em que o convencimento do outro depende de explicações/justificativas acerca de seu ponto de vista e de sua opinião; (iii) o funcionamento das temporais tem potencial sintomático de RE se se consideram as noções de tempo posterior, simultâneo e contingente, sua frequência e diversidade de usos, articuladas à natureza discursiva desses usos, ligados à imagem que o sujeito tem do relatar, como um processo em que se considera a proximidade icônica com o mundo real; e (iv) o funcionamento de tempo anterior tem potencial sintomático de $\mathrm{CO}$ se se consideram, no macrossistema temporal, os resultados de sua frequência e diversidade de usos, articulados à sua natureza discursivo-argumentativa, por meio dos quais o sujeito deixa rastros do que imagina ser um esquema argumentativo, recorrentemente constituído pela anterioridade de fatos que evidenciam suas afirmações e opiniões, deixando, ao mesmo tempo, rastros da construção de sua imagem como a daquele que tem conhecimentos do caso em discussão.

A face lacunar das TDs assume aspectos ainda mais específicos se se consideram as noções de contraste, concessão e finalidade, que não fornecem indícios diretos das TDs investigadas, mas mostram distintas formas de materialização, em relação à maior repetibilidade: dos complexos de dependência tática e abstração semântica, em CO; e dos contextos de trânsito semântico para a marcação dessas acepções, em RE.

A proposta teórico-metodológica deste trabalho permitiu considerar os MJs como rastros específicos da movimentação do sujeito na/para a construção de seu texto. Essas especificidades apontam, ao mesmo tempo, para o geral e o particular, a partir do que é fixo e lacunar nas tradições em que se inserem, em espaços de junção delineados pelo contexto enunciativo. Ao fazerem esse apontamento, lançam luz sobre a não obviedade da relação sintaxe-texto-discurso, quando tomada no espaço que retrata a textualização, caracterizada como acontecimento, em que o sentido do texto é construído na experiência [desse acontecimento], como retomada do já-experimentado, da memória do já-dito/escrito e do jáouvido/lido, mas também, e ao mesmo tempo, como novidade da reatualização de uma TD.

\section{Referências}

ABAURRE, M. B. M. Língua oral, língua escrita: interessam, à linguística, os dados da aquisição da representação escrita da linguagem? In: CONGRESSO INTERNACIONAL DA ALFAL, 9, 1990, Campinas. Anais... Campinas: IEL/Unicamp, 1990. p. 361-381. 
ASCHENBERG, H. Historische Textsortenlinguistik. Beobachtungen und Gedanken. In: DRESCHER, M. Textsorten in romanischen Sprachvergleich. Tubingen: Stauffenburg Verlag. S., 2002. p. 153-170.

CHACON, L. Ritmo da escrita: uma organização do heterogêneo da linguagem. 1996. 389 f. Tese (Doutorado em Linguística) - Programa de Pós-Graduação em Linguística, Universidade Estadual de Campinas, Campinas, 1996.

CORREAA, M. L. G. Arranjos referenciais de tempo em textos de pré-universitários: letramento e oralidade. Gragoatá, Rio de Janeiro, n. 25, p. 75-93, 2008.

CORRÊA, M. L. G. Heterogeneidade da escrita: a novidade da adequação e a experiência do acontecimento. Filologia e Linguística Portuguesa, São Paulo, v. 8, p. 269-286, 2007.

CORRÊA, M. L. G. O modo heterogêneo de constituição da escrita. São Paulo: Martins Fontes, 2004.

CORRÊAA, M. L. G. O modo heterogêneo de constituição da escrita. 1997. 435 f. Tese (Doutorado em Linguística) - Programa de Pós-Graduação em Linguística, Universidade Estadual de Campinas, Instituto de Estudos da Linguagem, Campinas, 1997.

COSERIU, E. O homem e sua linguagem. Rio de Janeiro, Presença, 1982.

COSERIU, E. Creatividad y técnica lingüística. Los tres niveles del lenguaje. In: COSERIU, E. Lecciones de linguística general. Madrid: Gredos, 1981. p. 269-286.

HALLIDAY, M. A. K. Above the clause: the clause complex. In: HALLIDAY, M. A. K. An introduction to Funcional Grammar. New York: Arnold; 1985.

KABATEK, J. Introduccion. In: KABATEK, J. (Ed.). Sintaxis histórica del español y cambio linguiístico: nuevas perspectivas desde las Tradiciones Discursivas. Madrid: Iberoamericana, 2008.

KABATEK, J. Sobre a historicidade dos textos. Linha d'água, v. 17, p. 157-170, 2006.

KABATEK, J. Tradiciones discursivas y cambio lingüístico. Lexis XXIX, v. 2, p. 151-177, 2005.

KOCH, P. Tradiciones discusivas y cambio lingüístico: el exemplo del tratamiento vuestra merced em español. In: KABATEK; J. (Ed.). Sintaxis histórica del español y cambio lingüístico. Madrid, Iberoamericana; 2008.

$\mathrm{KOCH}, \mathrm{P}$. Os falantes como lingüistas: tradición, innovación e interferencias no gallego actual. Salamanca: Edicions Xerais de Galicia, 1996.

KOCH, P; OESTERREICHER, W. Lingua hablada en la romania: Espanol, Francés, Italiano. Madrid: Editorial Gredos, 2007.

KORTMANN, B. Adverbial Subordination: a typology and History of Adverbial Subordinators Based on European Languagens. Berlin-New York, Mouton de Gruyter; 1997. 
LONGHIN-THOMAZI, S. R. Junção e(m) aquisição: aspectos morfossintáticos e cognitivos. Gragoatá, Niterói v. 30, p. 221-238, 2011.

LONGHIN, S. R. Tradições discursivas: conceito, história e aquisição. São Paulo: Cortez Editora, 2014.

LOPES-DAMASIO, L. R. O movimento linguístico-discursivo na aquisição da escrita: uma abordagem dos mecanismos de junção aditivos na construção de sentidos no texto. Filologia e Linguística Portuguesa, v. 21, p. 147-170, 2019.

LOPES-DAMASIO, L. R. Junção em contexto de aquisição de escrita: uma abordagem das tradições discursivas. Estudos Linguísticos, v. 43, n. 3, p. 1371-1386, 2014.

LOPES-DAMASIO, L. R; SILVA, P. C. S. Causa em aquisição da escrita: processos juntivos. Cadernos de Letras UFF, Niterói, v. 27, n. 55, p. 109-133, 2018.

MARCUSCHI, L. A. Oralidade e escrita. Texto da Conferência pronunciada no I Colóquio Franco-Brasileiro sobre linguagem e educação. UFRN, 26-28 de junho, 1995.

RAIBLE, W. Linking clauses. In: HASPELMATH, M. et al. (Ed.). Language typology and language universals: an international handbook. Berlin: Walter de Gruyter; 2001. p. 590617.

STREET, B. V. Literacy in theory and practice. Cambridge: Cambridge University Press, 1984.

TAURA, L. G. Tradição discursiva, variedade linguística e ensino. 2019. 153 f. Dissertação (Mestrado em Letras) - Programa de Pós-Graduação em Letras, Assis: Universidade Estadual Paulista, Assis, 2019.

\section{Sobre a autora}

Lúcia Regiane Lopes-Damasio (Orcid iD: https://orcid.org/0000-0002-9058-3566) Doutora e mestra em Linguística pela Universidade Estadual Paulista Júlio de Mesquita Filho (UNESP); graduada em Letras - Português/Italiano pela mesma instituição. É professora no Departamento de Estudos Linguísticos, Literários e da Educação, no Programa Nacional de PósGraduação em Letras e no Programa de Pós-Graduação em Estudos Linguísticos da UNESP. 